\title{
Membrane organization and tumorigenesis-the NF2 tumor suppressor, Merlin
}

\author{
Andrea I. McClatchey ${ }^{1,3}$ and Marco Giovannini ${ }^{2}$ \\ ${ }^{1}$ Massachusetts General Hospital, Center for Cancer Research and Harvard Medical School, Department of Pathology, \\ Charlestown, Massachusetts 02129, USA; ${ }^{2}$ Inserm U674, Fondation Jean Dausset-CEPH et Institut Universitaire \\ d'Hématologie, Paris, France
}

The NF2 tumor-suppressor gene was cloned more than a decade ago, but the function of its encoded protein, Merlin, remains elusive. Merlin, like the closely related ERM proteins, appears to provide regulated linkage between membrane-associated proteins and the actin cytoskeleton and is therefore poised to function in receiving and interpreting signals from the extracellular milieu. Recent studies suggest that Merlin may coordinate the processes of growth-factor receptor signaling and cell adhesion. Varying use of this organizing activity by different types of cells could provide an explanation for the unique spectrum of tumors associated with NF2 deficiency in mammals.

The identification of the genetic defect responsible for the familial cancer syndrome Neurofibromatosis type 2 (NF2) nearly 15 years ago yielded the unexpected prospect that the encoded tumor suppressor was a cytoskeleton-associated protein (Rouleau et al. 1993; Trofatter et al. 1993). This was in marked contrast to the known and now "classic" tumor suppressors p53, Rb, and NF1 that function either to directly control the cell cycle machinery in the nucleus, or in the case of NF1, to directly negatively regulate mitogenic Ras signaling (Sherr 2004). Several factors have rendered progress in defining the molecular basis of NF2-associated tumorigenesis slow, including the rare incidence of NF2 in humans, the paucity of $\mathrm{NF2}^{-/-}$cell lines and technical challenges in studying the NF2-encoded protein, Merlin, which is a novel type of tumor suppressor. However, recent advances, highlighted by the study of NF2 function in several different model organisms have begun to yield a model of Merlin function that offers important lessons about the origins and progression of cancer and provides novel insight into some basic biological principles. In

[Keywords: ERM proteins; Merlin/NF2; Schwann cells; ependyma; membrane organization; meninges]

${ }^{3}$ Corresponding author.

E-MAIL mcclatch@helix.mgh.harvard.edu; FAX (617) 726-7808.

Article and publication are at http://www.genesdev.org/cgi/doi/10.1101/ gad. 1335605 this review we have highlighted recent advances in understanding the pathology and molecular biology of NF2 with particular emphasis on the broader impact that the study of NF2 may have on the fields of tumor, cellular, and molecular biology.

The incidence of NF2 in humans is rare (fewer than one in 25,000 individuals) and the symptoms and phenotypes associated with NF2 are unusual and restricted (Evans et al. 2005). The hallmark of the disease is the development of Schwann cell tumors (schwannomas) on or around the vestibular branch of both eighth cranial nerves. Most NF2 patients go on to develop multiple schwannomas that are associated with other cranial nerves and spinal nerve roots, cranial and spinal meningiomas and, less frequently, intraspinal ependymomas. In contrast to other major human malignancies, these are benign, slow-growing tumors that respond poorly to chemotherapeutic intervention and cause significant morbidity. Indeed, the current standard of treatment remains local tumor control by repeated surgeries and radiation, which are often accompanied by damage of nerves and CNS structures (Evans et al. 1992).

Biallelic inactivation of the NF2 gene can also be identified in most sporadically occurring schwannomas (Stemmer-Rachamimov et al. 1997) and a large fraction of sporadically occurring meningiomas (Ruttledge et al. 1994; Lomas et al. 2005). In addition to tumors that are associated with familial NF2, NF2 mutations are frequently found in sporadic mesotheliomas of the lung lining that are associated with asbestos exposure (Bianchi et al. 1995; Sekido et al. 1995). More recently, NF2 mutations have been reported in some sporadic thyroid carcinomas, hepatocellular carcinoma cell lines, and perineurial tumors, revealing additional cell types affected by NF2 loss (Lasota et al. 2001; Pineau et al. 2003; Sheikh et al. 2004). The generation and study of Nf2-mutant strains of mice has further expanded the range of cancers associated with NF2 mutation and cell types affected by NF2 deficiency (see below). However, NF2 mutations have not yet been reported in many common/prevalent human cancers. As discussed below, these data raise the important question of whether there is a biological and/ 
or genetic basis for the unique spectrum of spontaneous tumors associated with NF2 mutation in humans and mice.

\section{A novel type of tumor suppressor}

Initial studies of the function of the NF2-encoded tumor suppressor, Merlin (also known as Schwannomin), were modeled after studies of other tumor suppressors and of the closely related ERM proteins (Ezrin, Radixin, and Moesin). Early studies confirmed, as for other tumor suppressors, that overexpression of Merlin can block both cell proliferation and oncogene-induced transformation (Tikoo et al. 1994; Lutchman and Rouleau 1995). Indeed, Merlin can negatively regulate cyclin D1 levels, consistent with the cell cycle arrest observed when Merlin is overexpressed (Xiao et al. 2002). However, given its predominant localization to the membrane:cytoskeleton interface, Merlin is not likely to directly control the cell cycle machinery. Instead, Merlin, like the ERM proteins, appears to provide regulated linkage between membraneassociated proteins and the actin cytoskeleton and thereby to function in membrane organization. Merlin is therefore a novel type of tumor suppressor poised to function in receiving and interpreting signals from the extracellular milieu.

\section{Model organisms}

The identification of NF2 homologs from other species and the functional characterization of their encoded proteins in other model organisms provides a valuable complement to the functional characterization of the mammalian NF2 protein. Genes similar to the human NF2 gene can be identified in many other metazoans, including invertebrates (Drosophila melanogaster, Anopheles gambiae, Caenorhabditis elegans, Xenopus laevis), fish (Danio rerio, Oryzias latipes), and birds (Gallus gallus). No NF2 homolog has been identified in Saccharomyces cerevisiae (yeast), suggesting that Merlin function is specific to the evolutionary branching of metazoans. The high degree of homology among metazoan NF2 gene products is complemented by the fact that they can be used interchangeably in functional studies, i.e., the human protein can function reliably in mouse and Drosophila model systems (LaJeunesse et al. 1998; Giovannini et al. 1999).

Several Nf2 mutant alleles that mimic naturally occurring human NF2 mutations have been engineered in the mouse, allowing a comparison of the phenotypic effects of these mutations in an animal model. Three different targeting approaches resulted in germline Nf2 homozygous mutants that were not viable (McClatchey et al. 1997; Giovannini et al. 2000). Nf2 null embryos fail early during embryonic development without initiating gastrulation (McClatchey et al. 1997). The underlying defect in $\mathrm{Nf}^{-/-}$embryos is not due to cell proliferation abnormalities in the embryo itself, but rather, the ab- sence of extra-embryonic structures that are required to generate a mesoderm-inducing signal. Notably, Merlin function is also required for normal development in the fruitfly, D. melanogaster and in the flatworm C. elegans (Fehon et al. 1997; J. Gervais, J. Satterlee, and A.I. McClatchey, unpubl.).

In the mouse, heterozygosity for any of the three mutant Nf2 alleles leads to a high incidence of bone tumors that exhibit loss of the wild-type Nf2 allele (McClatchey et al. 1998; Giovannini et al. 2000). Differences in the grade of malignancy observed in these tumors might be explained by the use of different genetic backgrounds. Indeed, some studies have indicated that Nf2 loss contributes to tumor metastasis (see below; McClatchey et al. 1997). Notably, $\mathrm{Nf}^{+/-}$mice are collectively predisposed to developing a variety of other tumor types at lower frequency, suggesting a broader role for Nf2 loss in tumorigenesis. None of the three strains of Nf2 heterozygous mutant mice spontaneously develop the classic clinical features of human NF2. However, consistent with the identification of NF2 mutations in asbestosinduced mesotheliomas in humans, $\mathrm{Nf2}^{+/-}$mice do show increased sensitivity to the carcinogenic effects of asbestos fibers. Intraperitoneal injection of asbestos fibers induces the formation of malignant mesotheliomas at a higher frequency in $\mathrm{Nf2}^{+/-}$mice than in wild-type mice (Fleury-Feith et al. 2003). Importantly, asbestos-induced tumors in $\mathrm{Nf2}^{+/-}$mice exhibit loss of the wild-type $\mathrm{Nf2}$ allele. These mice should be useful for further studies of the molecular pathogenesis, genetic modification, and environmental initiation of mesothelioma development.

Although Nf2 heterozygous mutant mice that genetically mimic human NF2 patients do not spontaneously develop schwannomas, inactivation of both Nf2 alleles specifically in Schwann cells (SCs) does yield manifestations of human NF2. Upon mating with transgenic $P 0$ Cre mice, in which the Cre recombinase is expressed specifically in SCs and in a subset of neural crest cells, $\mathrm{Nf2}$ conditional mutant $\left(\mathrm{PO}-\mathrm{Cre} ; \mathrm{Nf}^{\text {flox2/flox2}}\right)$ mice develop SC hyperplasia, SC tumors, cataracts, and cerebral calcifications (Fig. 1A,B; Giovannini et al. 2000). Moreover, mice with biallelic inactivation of $N f 2$ specifically in arachnoid cells develop a range of meningioma subtypes that are histologically similar to the human tumors (Kalamarides et al. 2002). Therefore, the lack of spontaneous schwannoma and meningioma development in $\mathrm{Nf2}^{+/-}$mice is not due to a fundamental difference in the function of mouse Merlin or in the biology of mouse Schwann and arachnoid cells, but instead to differences in the probability of loss of the wild-type allele in the cells from which schwannomas and meningiomas originate.

The growth-suppressing function of Merlin is conserved in other species. For example, somatic mosaic analysis reveals that clones of Mer homozygous mutant epithelial cells in the Drosophila eye hyperproliferate, providing a powerful system for carrying out genetic screens to identify modifiers of Nf2 deficiency (LaJeunnesse et al. 2001). Recent analyses of the chicken Merlin 

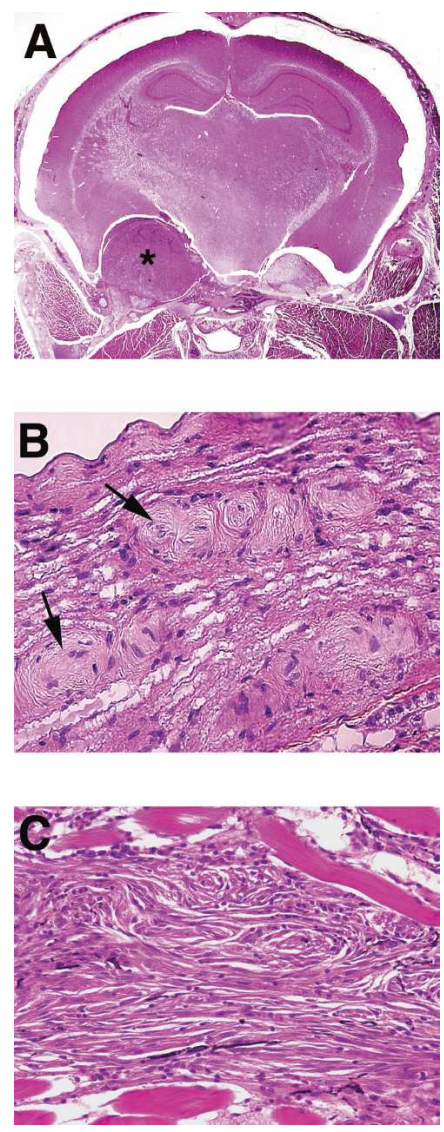

Figure 1. Loss of Merlin leads to SC hyperproliferation and tumorigenesis in animal models. (A) Hematoxylin and eosin (H\&E)-stained section of frank schwannoma emanating from the trigeminal nerve of a $\mathrm{PO}-\mathrm{Cre} ; \mathrm{Nf}^{\text {flox } 2 / f l o x 2}$ mouse $\left(^{*}\right) .(B)$ $\mathrm{H} \& \mathrm{E}$-stained section depicting SC hyperplasia in the sciatic nerve of a PO-Cre; $\mathrm{Nf2} 2^{\text {flox2/flox2 }}$ mouse. (C) Malignant peripheral nerve sheath tumor in Nf2a-mutant zebrafish. Zebrafish bearing a germline mutation in one allele of the NF2a gene develop spindle cell tumors that have features in common with nerve sheath tumors from other species (image kindly provided by K. Edepli) (Amsterdam et al. 2004).

homolog also confirm its function as a negative regulator of proliferation in vitro and in vivo (Chen et al. 2004a,b). The study of the Drosophila Merlin protein has also provided key insight into the regions of Merlin that are required for its localization and function (LaJeunesse et al. 1998). This also led to the identification and analysis of the so-called "Blue Box" mutant, $\mathrm{Mer}^{\Delta \mathrm{BB}}$, which is known to act in a dominant-negative manner and therefore to interfere with the activity of the wild-type protein. Ectopic expression of $\mathrm{Mer}^{\mathrm{\Delta B}}$ in the wing results in increased proliferation (LaJeunesse et al. 1998). Expression of the murine analog of $\mathrm{Mer}^{\mathrm{BB}}$ induces transformation of cultured NIH3T3 fibroblasts (Johnson et al. 2002). Interestingly, SC hyperplasia and tumors were observed in transgenic mice that express a patientderived mutant version of Merlin lacking amino acids 39-121 in SCs, indicating that this isoform, when overexpressed, may also have dominant-negative properties
(Giovannini et al. 1999). Therefore, when overexpressed, certain mutant versions of Merlin exhibit oncogenic properties. However, in human tumors, where expression of mutant NF2 alleles is controlled by endogenous regulatory sequences, the same mutant Merlin isoforms must be unstable, resulting in a loss of function rather than a dominant oncogenic effect (Gautreau et al. 2002). Delineation of the regions of Merlin that are necessary for the dominant negative activity of overexpressed Merlin may provide novel mechanistic insight into Merlin function.

The different strains of Nf2 mutant mice also provide powerful tools for investigating genetic cooperativity in tumorigenesis. The identification of tumor suppressor or other gene mutations that cooperate with $N f 2$ loss can provide important mechanistic insight into Nf2-associated pathways. Dramatic cooperativity between the $N f 2$ and $p 53$ tumor suppressor gene mutations is displayed by $\mathrm{Nf2} 2^{+/-} ; \mathrm{p53}^{+/-}$cis mice that carry heterozygous $\mathrm{Nf2}$ and p53 mutations on the same chromosome; these mice develop multiple osteosarcomas early in life (McClatchey et al. 1998). Notably, $\mathrm{Nf2^{+/- }} ; \mathrm{p} 53^{+/-}$trans mice develop fewer tumors with longer latency; therefore genetic linkage of cancer predisposing mutations can profoundly influence tumorigenesis. In conditional Nf2 mutant mice, p53 heterozygosity can also markedly increase the incidence of SC-derived malignant peripheral nerve sheath tumors (MPNSTs) (Robanus-Maandag et al. 2004). Importantly, the timing of Nf2 inactivation seems to determine in which neural crest-derived cell type the growth advantage occurs since, in contrast to

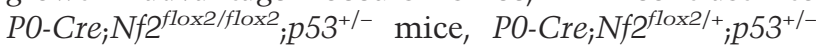
cis mice develop osteogenic but not SC tumors. This difference in tumor spectrum could be simply explained

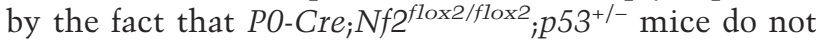
require an additional event for biallelic inactivation of Nf2 and SC hyperproliferation; in the PO-Cre; $\mathrm{Nf2}^{\text {flox2/+ }}$; $p 53^{+/-}$cis mice, spontaneous loss of the wild-type $N f 2$ allele may occur more rapidly in osteoblasts than in SCs. Alternatively, this difference could reflect cell-type-specific consequences of sequential versus simultaneous loss of Nf2 and p53 function. Perhaps Nf2 deficiency leads to p53-dependent growth arrest or apoptosis in OBs but not SCs. Finally, early biallelic Nf2 loss in $\mathrm{PO}-\mathrm{Cre} ; \mathrm{Nf2} \mathrm{flox} 2 / f l o x 2$ p $53^{+/-}$mice could specifically target a population of SC progenitors that are particularly sensitive to loss of Merlin function.

More recently, the role of NF2 and p53 mutations in SC tumorigenesis has been emphasized by the observation of MPNST development in NF2 (Amsterdam et al. 2004) and p53 (Berghmans et al. 2005) mutant zebrafish (Fig. 1C). Although p53 mutations are found in human MPNSTs, it is interesting to note that in NF2 patients, benign SC tumors initiated by biallelic NF2 gene inactivation do not progress into MPNSTs (see below). Indeed, malignant transformation of a schwannoma is an exceedingly rare event and analysis of the few cases reported in the literature show that none of the patients had NF2 (Woodruff et al. 1994; McMenamin and Fletcher 2001). 


\section{Regulation of Merlin}

\section{Structure}

Many studies have established parallels between Merlin and the ERMs. Central to Merlin function is the fact that like the ERM proteins, Merlin can undergo regulated intramolecular self-association (Gonzalez-Agosti et al. 1996; Sherman et al. 1997; Gronholm et al. 1999; Nguyen et al. 2001). Several recent structural studies have yielded complementary models of Merlin and ERM tertiary conformation. The $1.9 \AA$ crystal structure of the complexed N-terminal FERM (Four-point-one, Ezrin, Moesin, Radixin) and C-terminal tail domains of mammalian Moesin reveals that the C-terminal tail adopts an extended conformation to interact with the trilobed FERM domain, masking potential binding sites of other proteins (Pearson et al. 2000). Most $(\sim 81 \%)$ of the residues that are conserved between Merlin and the ERM proteins map to this interface, indicating that Merlin likely adopts a similar conformation. Indeed, the structure of the isolated Merlin FERM domain is very similar to that of the ERMs (Shimizu et al. 2002). Although most human NF2 mutations identified are deletions or truncating mutations that effect complete loss of function, missense mutations do occur and are distributed throughout the FERM domain and C-terminal tail, suggesting that Merlin function is highly dependent upon the tertiary configuration of the entire protein (Pearson et al. 2000). Mutations that disrupt self-association likely also alter Merlin localization and protein interactions. Like the ERMs, Merlin self-association is regulated, at least in part, by phosphorylation (see below).

\section{Post-translational modification}

An increasing number of studies have examined the regulation of Merlin by phosphorylation. It was recognized early on that the two major isoforms of Merlin visualized by SDS-PAGE and immunoblotting represent differentially phosphorylated species (Shaw et al. 1998). Although Merlin is phosphorylated on multiple residues, phosphorylation of a single serine residue, S518, causes the mobility shift and has therefore been best studied (Shaw et al. 2001; Kissil et al. 2002; Xiao et al. 2002; Rong et al. 2004). Available data suggest that S518 phosphorylation weakens self-association and inactivates the growth-suppressing function of Merlin. Phosphorylation of Merlin at S518 is regulated by specific cell culture conditions, including cell density, cell:substrate attachment, and growth factor availability (Shaw et al. 1998). The best-studied stimulus for Merlin S518 phosphorylation is activation of the small GTPase Racl (Shaw et al. 2001). Rac-induced phosphorylation of Merlin S518 appears to be mediated by the major Rac effector p21-activated kinase (Pak) (Kissil et al. 2002; Xiao et al. 2002). Interestingly, S518 can also be phosphorylated in a Pakindependent manner by protein kinase A (PKA) (Alfthan et al. 2004), suggesting that disparate stimuli regulate Merlin. Similarly, multiple signals appear to induce phosphorylation of a conserved C-terminal threonine residue in the ERM C-terminal tail (Matsui et al. 1998, 1999; Pietromonaco et al. 1998; Hipfner et al. 2004). Virtually nothing is known about the regulation or functional consequences of phosphorylation of other Merlin residues. Finally, phosphatidylinositol 4,5-bisphosphate $\left(\mathrm{PIP}_{2}\right)$ binding to the FERM domain is thought to cooperate with phosphorylation in weakening self-association during ERM activation; the mapped ERM PIP 2 -binding sites are conserved in Merlin, suggesting that $\mathrm{PIP}_{2}$ binding may also play an important role in regulating Merlin function (Barret et al. 2000). Collectively, these studies suggest that the cell may integrate multiple strategies to fine-tune the localization and activity of Merlin.

\section{Subcellular localization}

If Merlin's ability to organize membrane domains is central to its function as a tumor suppressor, then it is critical to define where Merlin is localized within the cell. This has been particularly challenging due to the low levels of endogenous Merlin in most cell types and to the insolubility of a substantial pool of Merlin. As a consequence, many studies have examined the localization of exogenous (overexpressed), often epitope-tagged Merlin, which may not fully mirror the endogenous protein. In Drosophila epithelia, endogenous Merlin is concentrated in the subapical junctional region, where it overlaps with the more apically localized Moesin (Bretscher et al. 2002). Similarly, in the C. elegans intestinal epithelium, exogenous nfm-1, the Merlin paralog, localizes basolaterally relative to erm-1 (Gobel et al. 2004). In cultured mammalian cells, endogenous and exogenous Merlin is concentrated in actin-rich structures such as membrane ruffles in isolated cells and along cell:cell boundaries as they form, consistent with its role in mediating contactdependent inhibition of proliferation (see below; Gonzalez-Agosti et al. 1996; Maeda et al. 1999; Lallemand et al. 2003). Although the localization of Merlin in polarized mammalian epithelial cells has not been reported, Merlin localizes to synaptic junctions in cultured polarized neurons (Gronholm et al. 2005). In addition to concentrated localization to cell protrusions and cell:cell boundaries, some Merlin also exhibits diffuse localization throughout the membrane or cytoplasm and sometimes a punctate distribution that has been attributed to localization to intracellular vesicles or membrane lipid rafts (McCartney and Fehon 1996; Stickney et al. 2004). Indeed, vesicular and/or lipid raft localization would be consistent with a number of lines of recent evidence suggesting a role for Merlin in the endocytic trafficking of membrane receptors (see below). Finally, Merlin has recently been reported to localize to the nucleus in cultured cells under certain conditions (Kressel and Schmucker 2002; Muranen et al. 2005). It is not yet clear whether Merlin has an activity in the nucleus. However, the sum of the available data are consistent with the notion that Merlin normally carries out its growth-suppressing activity from the cell periphery; perhaps Merlin is removed from the periphery and sequestered in the 
nucleus during conditions of exponential proliferation. Conversely, Merlin could help to sequester growth-promoting factors outside of the nucleus during conditions of growth arrest.

\section{Pathways/activities}

The NF2 field is at a critical juncture, passage of which will require innovative approaches to delineating the molecular basis of Merlin's function as a tumor suppressor. Many Merlin-interacting proteins have been reported-most of which also interact with the ERM proteins-and many cellular and molecular activities have been attributed to Merlin. However, follow-up functional studies of many of these putative interactors have not been forthcoming, perhaps due to the aforementioned technical challenges associated with isolating and localizing Merlin. The fact that a substantial fraction of Merlin is insoluble and that Merlin solubility is regulated, present biochemical challenges to ascribing functional significance to specific Merlin-associated proteins. Nevertheless, the Merlin-interacting proteins and phenotypic consequences of Merlin overexpression can be organized into several pathways that appear to be controlled by Merlin. Indeed, a key question is whether Merlin performs multiple independent functions, one of which is critical in tumor suppression, or whether Merlin controls a specific combination of pathways that collectively impart tumor suppression.

\section{Rho GTPases}

The function of Merlin and the ERM proteins has been linked to that of the Rho family of small GTPases that control actin cytoskeleton remodeling (for review, see Bretscher et al. 2002; McClatchey 2003). Central to the functional relationships between Merlin/ERMs and Rho GTPases are reciprocal modes of regulation. Thus, in addition to the role of Rac in regulating Merlin phosphorylation described above, overexpression of Merlin negatively regulates Rac-dependent signaling and $\mathrm{Nf}^{-/-}$cells display phenotypes that are observed in cells expressing activated Rac alleles (Shaw et al. 2001). Similarly, in addition to Rho-dependent ERM phosphorylation, loss of the single Drosophila ERM protein Moesin, leads to elevated Rho signaling (Speck et al. 2003). Although the mechanism whereby Merlin/ERMs control Rho/Rac activity is not yet clear, Merlin/ERMs have been shown to physically interact with Rho guanine-dissociation inhibitor (RhoGDI) (Takahashi et al. 1997; Maeda et al. 1999). Like the ERMs, Merlin interaction with RhoGDI could counteract RhoGDI-mediated inhibition and sequestration of Rho or Rac in the cytosol, thereby effecting activation of Rho or Rac signaling. Alternatively, recent evidence suggests that Merlin can bind to and directly negatively regulate Pak itself (Kissil et al. 2003). This latter model predicts that Merlin does not regulate Rac-effector pathways that are Pak independent.

\section{Actin remodeling}

A key aspect of Merlin function that must be delineated is its functional association with the actin cytoskeleton. Merlin, like the ERMs, localizes to specific regions of cortical actin remodeling (den Bakker et al. 1995; Gonzalez-Agosti et al. 1996; Sainio et al. 1997). In contrast to the ERMs, Merlin does not have an actin-binding domain at the $\mathrm{C}$ terminus, but instead may bind actin directly via an N-terminal domain (Brault et al. 2001; James et al. 2001). Alternatively, interaction of Merlin with the actin cytoskeleton may occur indirectly via the cytoskeletal proteins $\beta$ II spectrin, paxillin or the ERM proteins themselves (Scoles et al. 1998; Gronholm et al. 1999; Meng et al. 2000; Nguyen et al. 2001; FernandezValle et al. 2002). Loss of Merlin function in SCs and keratinocytes yields marked changes in the morphology of the actin cytoskeleton (Pelton et al. 1998; Lallemand et al. 2003; A. Chan, D. Lallemand, A.I. McClatchey, and M. Giovannini, unpubl.). Similarly, loss of ERM function can lead to dramatic alterations in the cortical actin cytoskeleton (Speck et al. 2003). Although these phenotypes could be an indirect consequence of altered RhoGTPase activity as described above, Merlin may also directly control actin cytoskeleton remodeling. In fact, it has recently been reported that Merlin and the ERMs can directly interact with and inhibit the function of N-WASP, which normally controls activation of the actin nucleator Arp2/3 (Manchanda et al. 2005). The Arp2/3 complex nucleates actin subunits and drives actin filament branching in specialized cortical domains such as the membrane ruffle and adherens junction (AJ) where Merlin is concentrated (Bershadsky 2004).

\section{Contact inhibition/cell:cell adhesion}

Several studies suggest that Merlin can control contactdependent inhibition of proliferation (Morrison et al. 2001; Johnson et al. 2002; Lallemand et al. 2003). Indeed, the key consequence of Merlin deficiency in cultured primary cells of several types is their failure to undergo contact-dependent inhibition of proliferation (Lallemand et al. 2003). Merlin phosphorylation and levels are regulated by cell density and Merlin localizes to nascent boundaries between cells as they form, suggesting a role in cell:cell communication (Shaw et al. 1998; Lallemand et al. 2003). Merlin may regulate contact-dependent inhibition of proliferation through interaction with the hyaluronic acid receptor CD44 in some cell types (Morrison et al. 2001). Alternatively, Merlin associates with and is required for the formation of stable cadherin-containing AJs between cells of several types (Lallemand et al. 2003). In this setting, Merlin appears to stabilize the final AJ structure in association with the actin cytoskeleton. The mechanistic basis of contact-dependent inhibition of proliferation of any cell type is poorly understood and the study of Merlin may provide novel insight into this important biological phenomenon. Moreover, it is well established that defective cell:cell communication can contribute to both tumor initiation and metas- 
tasis, providing an explanation for the tumorigenic and metastatic consequences of Nf2 deficiency in humans and mice.

\section{Growth-factor/membrane-receptor signaling}

Several lines of evidence suggest that Merlin can regulate receptor tyrosine kinase activity and perhaps trafficking. For example, genetic interactions between a $\mathrm{Mer}$ mutation and EGFR pathway mutations have been documented in Drosophila (LaJeunesse et al. 2001). In addition, Merlin has been reported to physically interact with several proteins with established roles in growthfactor receptor signaling. Thus, Merlin can form a ternary complex with a novel protein dubbed Magicin and Grb2, an adaptor that coordinates receptor tyrosine kinase and Ras signaling (Wiederhold et al. 2004). Merlin can also interact with EBP50/NHE-RF1, which can, in turn, interact with Erbin; both proteins are PDZ-domain containing adaptors that have been implicated in the membrane distribution of receptor tyrosine kinases (Murthy et al. 1998; Kolch 2003; Lazar et al. 2004; Rangwala et al. 2005). Similarly, Ezrin has been reported to interact with Lin-7/Pals1, which controls ErbB2 membrane distribution in C. elegans (Shelly et al. 2003; Cao et al. 2005). Moreover, Merlin can inhibit EGFR internalization and signaling upon cell:cell contact ( $M$. Curto and A.I. McClatchey, unpubl.). A role for Merlin in later stages of endocytosis is suggested by its reported ability to interact with Hepatocyte Growth-Factor Receptor Substrate (HRS), which controls lysosomal trafficking of membrane receptors including the EGFR (Scoles et al. 2000). The localization of Merlin to vesicular structures under some conditions in Drosophila and mammalian cells together with its reported localization to lipid rafts further supports a role in membrane receptor trafficking (McCartney and Fehon 1996; Stickney et al. 2004). Regulation of growth-factor receptor surface availability and endocytosis would be a plausible mechanism whereby Merlin could control cell proliferation. The study of Merlin function could thus provide a novel insight into growth-factor receptor signaling and trafficking in normal cells and suggest novel avenues of growth-factor receptor deregulation in tumors.

\section{Different complexes for different purposes or coordination of signaling from multiple membrane complexes?}

If endogenous Merlin does control multiple different pathways as described above, this could reflect independent functions or a role for Merlin in coordinating signaling from multiple membrane complexes. Perhaps the accumulation of growth inhibitory signals from multiple Merlin-associated membrane complexes ultimately reaches a threshold that halts proliferation (Fig. 2). This threshold could vary in different cell types or contexts. For example, Merlin could stabilize large, actin-cytoskeleton-associated membrane-signaling complexes such as
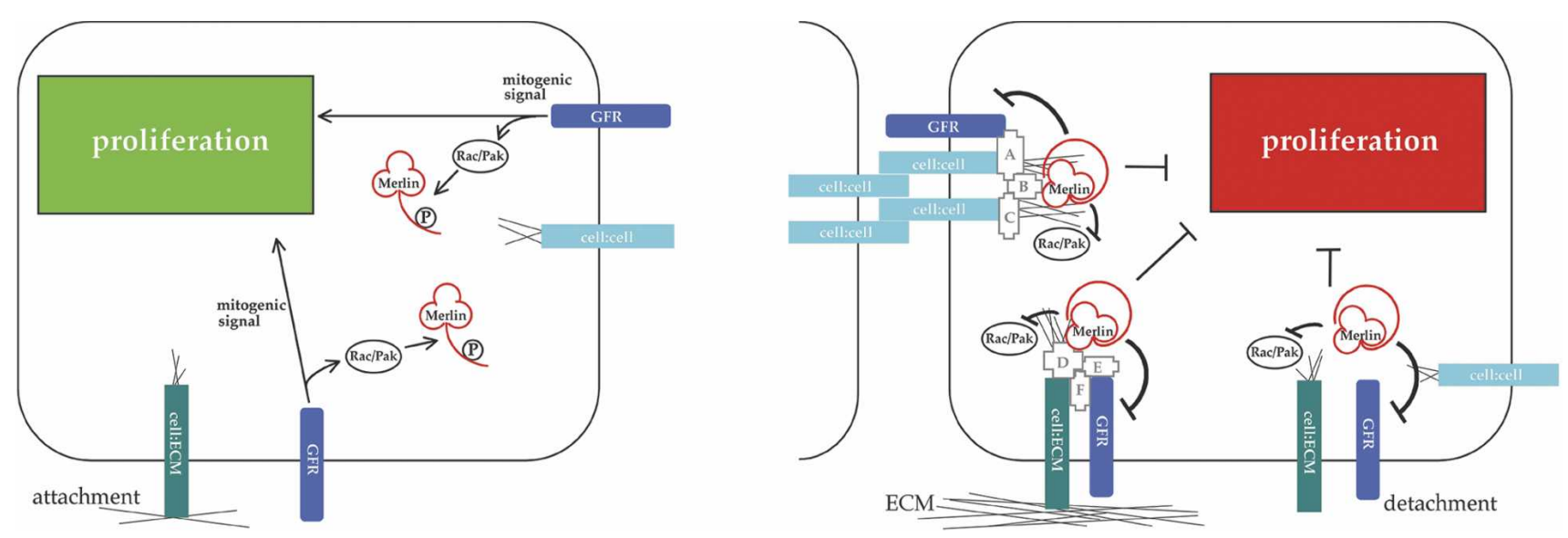

Figure 2. Merlin-organized complexes prevent mitogenic signaling and contact-dependent inhibition of proliferation. (Left) At low cell density in cell culture, Merlin is predominantly hyperphosphorylated and inactive and mitogenic signaling proceeds. Similarly, upon cell reattachment to certain ECM substrates, a pool of Merlin is rapidly phosphorylated. (Right) At high cell density in cell culture, Merlin is hypophosphorylated, self-associated, and active in mediating contact-dependent inhibition of proliferation. Merlin is recruited to nascent cell:cell boundaries where it appears to stabilize AJs between cells, perhaps by inhibiting Rac/Pak signaling and/or stabilizing the actin cytoskeleton. Under these conditions, Merlin may inhibit signaling from AJ-associated growth-factor receptors. Hypophosphorylated Merlin can also interact with cell:ECM receptors such as CD44, which binds to hyaluronic acid (HA); increased CD44:HA interaction with increased cell density leads to high levels of active Merlin, which may inhibit associated growth-factor receptors. Notably, complete cell detachment also leads to hypophosphorylation and activation of Merlin. Perhaps inhibited mitogenic signaling from multiple complexes accumulates, reaching a threshold that halts proliferation. The study and manipulation of cell:cell contact in two dimensions in cell culture is nonphysiological; in vivo cells in a tissue are contacting other cells and can override contact-dependent inhibition of proliferation under certain normal conditions or in the context of a tumor. Merlin may coordinate the receipt of physical information from the extracellular milieu with the receipt and processing of mitogenic stimuli. 
the AJ by locally inhibiting Rac-Pak signaling and/or WASP-mediated actin filament protrusion. Increasing evidence suggests that growth-factor receptors physically associate with and are regulated by AJs (Takahashi and Suzuki 1996; Lampugnani et al. 2003; Qian et al. 2004). Merlin could also organize CD44-containing complexes that coordinate cell:ECM attachment and proliferation control; in addition to Merlin and Ezrin, CD44 can be found in complexes containing growth-factor receptors (Morrison et al. 2001; Cavallaro and Christofori 2004). A fundamental mechanism by which growth-factor receptors are regulated is via endocytosis. Both cel1:ECM and cell:cell junctions are dynamic structures that also undergo regulated endocytic turnover. Perhaps by combining the turnover of adhesion structures with growth-factor receptors, the cell can coordinate cell adhesion stability with inhibition of mitogenic signalingMerlin could function to integrate the two. This would be consistent with the observation that Merlin both controls AJ stability and prevents EGFR internalization (M. Curto and A.I. McClatchey, unpubl.) and with the reported role for Erbin in controlling both $\mathrm{AJ}$ formation and proliferation in SCs (Rangwala et al. 2005). Indeed, the study of Merlin could provide novel insight into the poorly understood mechanism whereby cells coordinate growth-factor receptor signaling and AJ turnover.

\section{Schwann, arachnoid, ependymal, and mesothelial cells-unique properties?}

Most tumor-suppressor genes including NF2 are expressed broadly, providing little explanation for the restricted tumor spectrum exhibited by heterozygous mutant carriers. The predisposition of humans and mice that carry heterozygous tumor-suppressor gene mutations to certain types of tumors could be due to (1) celltype-specific differences in the temporal occurrence of obligatory genetic events such as loss of the wild-type Nf2 allele or cooperating mutations; (2) cell-autonomous differences in dependence of various cell types upon Merlin for proliferation control, perhaps due to differential expression of key components of a particular tumorsuppressor pathway such as associated proteins, regulators, downstream targets or proteins with partially or fully redundant functions; or (3) non-cell-autonomous differences in the contribution of surrounding heterozygous mutant tissue to tumorigenesis as has been demonstrated for NF1-associated tumors (Zhu et al. 2002).

Indeed, there is ample evidence for cell-type-specific consequences of $N f 2$ deficiency. For example, although several types of $\mathrm{Nf2}^{-/-}$cells hyperproliferate in vivo, hyperproliferation is not a consequence of $N f 2$ deficiency in Nf2-null mouse embryos as described above (McClatchey et al. 1997). Similarly, in the fly and in mosaic $\mathrm{Nf2}^{-/-} \leftrightarrow$ wild-type mouse embryos $\mathrm{Nf2}$ deficiency leads to defects in many tissues, but hyperproliferation in only certain contexts in vivo (Fehon et al. 1997; LaJeunnesse et al. 1998; MacDougall et al. 2001; A.I. McClatchey, unpubl.). In some types of cultured cells (i.e., keratinocytes and SCs), but not others (fibroblasts, osteoblasts), loss of Merlin yields dramatic alterations in actin cytoskeleton morphology (Pelton et al. 1998; Lallemand et al. 2003; A. Chan, D. Lallemand, A.I. McClatchey, and M. Giovannini, unpubl.). Finally, stable AJs do not form at all in cultured $\mathrm{Nf2}^{-/-}$fibroblasts, osteoblasts, SCs, and keratinocytes, while more subtle defects in AJ stability and cell:cell communication are apparent in other $\mathrm{Nf2}^{-/-}$ epithelial cells (A.I. McClatchey and M. Curto, unpubl.). Defective cell:cell communication is a consequence of Nf2 defiency in many different cell types. Are Schwann, arachnoid, ependymal, and mesothelial cells particularly dependent upon Merlin for integrating cell:cell communication with inhibition of cell proliferation?

SCs are neural crest-derived cells that undergo a sophisticated program of movement and differentiation as they associate with and insulate peripheral axons. Neural crest cells that migrate from the dorsal neural tube to the sensory ganglia and to positions along emerging peripheral axon bundles become immature SCs (for review, see Garratt et al. 2000). Both immature and mature SCs assume an exquisite degree of compartmentalization that is coordinated by intra- and intercellular junctions (Salzer 2003). Dividing immature SCs first loosely ensheath and then progressively segregate clusters of axons from one another with extensive cytoplasmic processes. The initial extension of SC processes along axons and communication between adjacent SCs appear to be mediated by $\mathrm{N}$-cadherin; this association is required for contact-dependent signaling in SC proliferation and differentiation (Salzer et al. 1980a,b; Garratt et al. 2000). The mature peripheral nervous system contains both myelinating and nonmyelinating SCs. Nonmyelinating SCs continue to invest multiple unmyelinated axons. In contrast, myelinating SCs stretch to wrap a single axon multiple times, forming intracellular AJs between adjacent loops of membrane at the paranode and between internodal layers at Schmidt-Lanterman incisures (Fig. 3A; Salzer 2003). At the paranode, the terminal loops are attached to the axonal membrane via septate-like junctions that compartmentalize the axonal surface (for review, see Peles and Salzer 2000; DenisenkoNehrbass et al. 2002). Merlin has been reported to localize to both the paranode and Schmidt-Lanterman incisures of myelinating SCs (Scherer and Gutmann 1996). Ultrastructural examination of sciatic nerves in $\mathrm{PO}$-Cre; $N f 2^{f l o x} 2 / f l o x 2$ mice revealed markedly abnormal myelination, although it is not clear whether these abnormally myelinating cells are the precursors of schwannoma development (Giovannini et al. 2000). In fact, human schwannomas do not commonly contain compact myelin (Erlandson and Woodruff 1982). As discussed below, a key issue for the study of NF2-associated tumorigenesis is defining the type of SC that gives rise to a schwannoma.

SCs are critically dependent upon signaling via the ErbB (EGFR) family of receptors for their survival, proliferation, and differentiation (for review, see Garratt et al. 2000). In general, ErbB-expressing SCs and their precursors respond to axonally derived neuregulin, the major functional ErbB ligand in the peripheral nervous sys- 
Figure 3. Specialized architecture of Schwann, arachnoid, and ependymal cells. (A) Myelinated fiber sectioned through the paranodal region of a node of Ranvier. Septate-like junctions form between each paranodal loop and the axon (arrowhead), while tight junctions and AJs form between adjacent loops (arrow). Bar, $500 \mathrm{~nm}$. (Image kindly provided by Carmen Diaz.) $(B$, left $)$ H\&E-stained section depicting the arachnoid epithelium in the context of the three meningeal layers. (Bo) Bone; (DM) dura mater; (A) arachnoid; (SAS) subarachnoid space; $(\mathrm{PM})$ pia mater; $(\mathrm{Br})$ brain parenchyma (cerebral cortex). The arachnoid normally adheres to the inner surface of the dura, the space between them is a tissue-processing artifact. (Right) Schematic depicting the loosely interdigiting processes of the arachnoid epithelium that are connected by tight junctions and AJs (red). The direction of cerebrospinal fluid (CSF) transit through the arachnoid is shown (arrow). (C, left) The central canal of the spinal cord is lined by intraspinal ependymal cells (H\&E staining). (Right) Schematic depicting the cellular architecture of the ependyma. Ependymal epithelial cells are connected by a complex series of apical AJs (red) (Peters et al. 1991). Tight junctions can be identified between cells in some regions of the ependyma, where they are often situated at the basal end of the cell (red). Tight junctions are also found in association with tanycytes, specialized bipolar cells that are inserted into the ependyma in certain regions. CSF transits from the spinal canal across the ciliated apical (lower in this figure) surface of the ependyma.
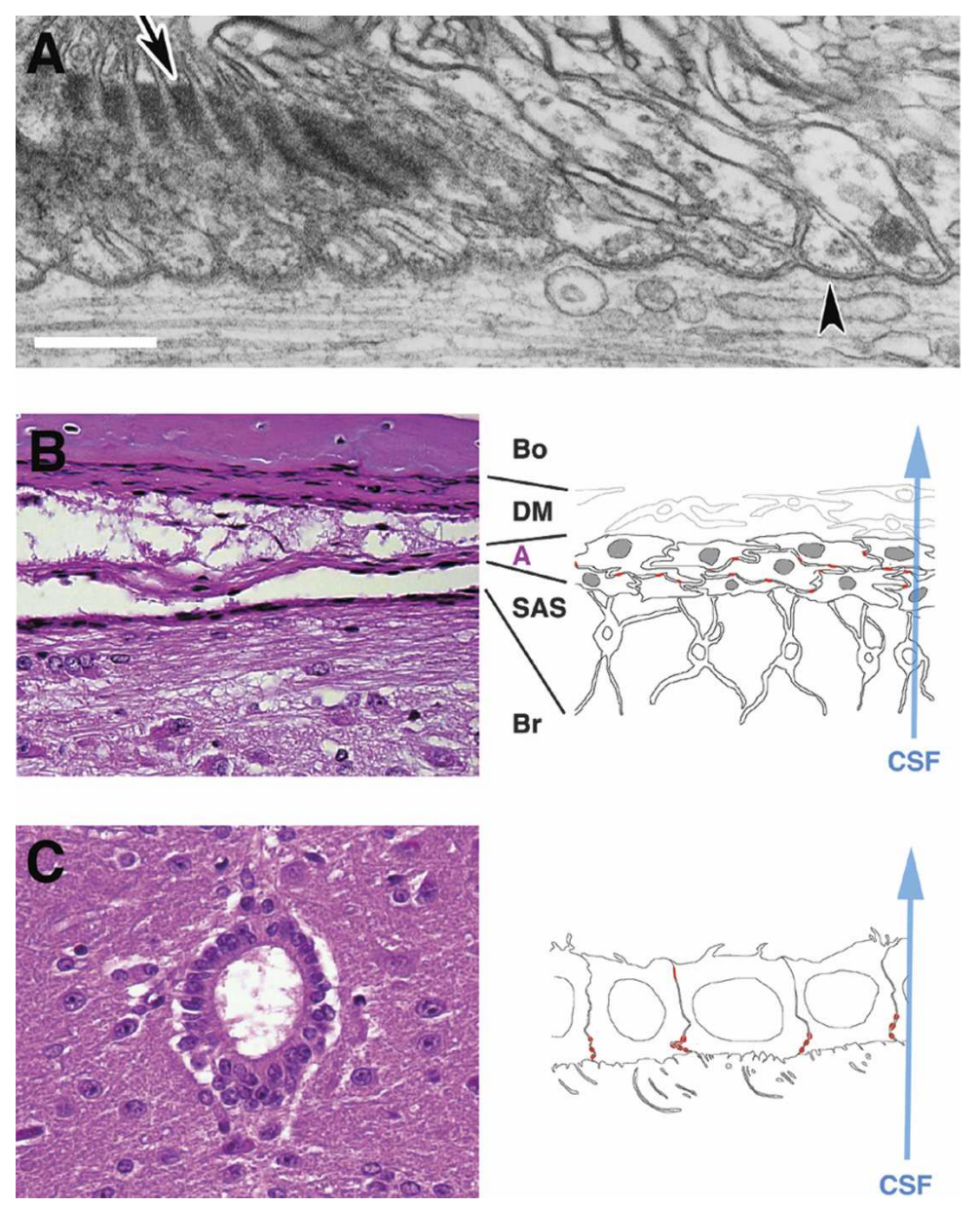

tem. In fact, ErbB signaling regulates myelin thickness by controlling the number of successive wraps made by individual SCs (Garratt et al. 2000; Michailov et al. 2004). Reduced ErbB signaling effects hypomyelination (fewer wraps) and excess ErbB signaling effects hypermyelination (more wraps). In this unique setting, intracellular communication between wraps and growth-factor receptor signaling must be coordinated and may be particularly sensitive to Merlin loss.

Much less is known about the molecular control of proliferation and cell:cell communication in the developing and mature meninges and ependyma. The arachnoid membrane lies between the outer dura and inner pia mater, collectively forming the meningeal layers that cover the brain and spinal cord (Fig. 3B; Yamashima 1996). Meningiomas tend to arise from arachnoid cells (also termed meningothelial cells) located within arachnoid villi, specialized projections that have an important role in the transport of cerebrospinal fluid (Louis et al. 2000). It has been reported that the number of E-cadherin-containing AJs is decreased in many meningiomas (Tohma et al. 1992; Yamashima et al. 1992). In fact, NF2 patients predominantly develop a particular type of meningioma known as the fibroblastic meningioma that lacks strong epithelial characteristics (Heinrich et al. 2003).
The ependymal epithelium lines the ventricles of the brain and central canal of the spinal cord and is a remnant of the proliferative ventricular zone that gives rise to most neurons and glia of the central nervous system during development (Fig. 3C; Peters et al. 1991). Together with the choroid plexus, these cells form the brain:cerebrospinal fluid (CSF) interface; in contrast to the major function of the adjacent choroid plexus in CSF secretion, the ependyma plays an important role in CSF transport (Del Bigio 1995). NF2 mutations are associated with intraspinal ependymomas rather than intracranial ependymomas (Ebert et al. 1999). Notably, the spinal, but not cranial ependyma is capable of proliferative regeneration following injury (Nag 1997).

Both the arachnoid and ependyma are simple epithelia that are in contact with and involved in transport of CSF, which is a source of certain growth factors (Redzic and Segal 2004). The arachnoid is often described as a "delicate" epithelium. Ultrastructurally, normal arachnoid cells are characterized by loosely interdigitating cellular processes connected by junctional complexes; between the cellular processes are tunnels of extracellular space (Fig. 3B; Peters et al. 1991; Yamashima 1996). Ependymal cells form a simple ciliated cuboidal epithelium connected by apical adherens and gap junctions (Fig. 3C; Lagunowich et al. 1992; Lippoldt et al. 2000). Notably, 
some studies have concluded that the ependyma is a "leaky" epithelium, perhaps due to the lack of tight junctions between cells in some regions of the ependyma (Gotow and Hashimoto 1982). Interestingly, the mesothelial lining also performs a critical active function in fluid transport across the peritoneal and pleural cavities. Therefore, like the arachnoid and ependyma, the mesothelia are designed to allow the passage of fluid. All three epithelia must both delimit a fluid-filled space and allow active transit of fluid. Could the histoarchitectural requirements of such epithelia be particularly sensitive to loss of Merlin? Could Merlin be particularly important for preventing signaling from growth-factor receptors that are exposed to a constant source of ligand in cells with loose or permeable intercellular junctions?

The most consistent phenotype associated with Nf2 deficiency in cultured cells is loss of contact-dependent inhibition of proliferation. In a developing organism, cells in the context of a tissue are all in contact with other cells, but can divide and, therefore, override contact-dependent inhibition of proliferation at certain times. It is likely that cells in most adult tissues integrate multiple inhibitory signals to maintain contactdependent inhibition of proliferation; perhaps certain cell types rely more heavily upon Merlin for this function. In mice and perhaps in humans, loss of Nf2 is sufficient for hyperproliferation of SCs and arachnoid cells in vivo, although at least one additional mutation is likely required for frank tumor formation. Animal models of $N f 2$ deficiency in the ependyma have not yet been described. Notably, Nf2-associated shwannomas, meningiomas, and ependymomas are benign tumors that do not progress to malignancy, perhaps reflecting physiological loss of contact-dependent inhibition of proliferation in vivo. In contrast, osteosarcomas and other tumors that spontaneously develop with longer latency in $\mathrm{Nf2}^{+/-}$mice are malignant and metastatic, likely reflecting the cooperative loss of Nf2 function and that of other growth inhibitory signals. Benign, slow-growing tumors represent a special therapeutic challenge, as standard chemotherapeutic strategies target rapidly dividing cells. In addition, it is well established that cells from malignant tumors are often particularly sensitive to the induction of apoptosis, a feature that is exploited by many chemotherapeutic agents (Johnstone et al. 2002).

\section{Future directions/perspectives}

There are many exciting directions and challenges ahead for the study of Nf2-associated tumorigenesis and the molecular function of Merlin. The study of $N f 2$ function in animal models has extended our view of Merlin beyond its role in tumor suppression and revealed that Merlin function is essential in many different types of cells. In fact, functional studies of Merlin have already provided new insight into fundamental biological processes such as contact-dependent inhibition of proliferation, cell:cell communication, receptor trafficking, actin cytoskeleton remodeling, and membrane organization.

The study of Nf2-mutant mice suggests that loss of
Merlin function could play an unexpectedly broad role in tumorigenesis and metastasis. Studies of tumorigenesis in these mice have revealed that both genetic and biological parameters can dictate the spectrum of spontaneous tumors associated with heterozygous $\mathrm{Nf2}$ mutation. Thus, linkage of cancer-predisposing mutations, temporal control of Nf2 loss, and cell-type-specific phenotypic consequences of Nf2 deficiency can each profoundly impact spontaneous tumor development in $\mathrm{Nf2}^{+/-}$mice. These principles are broadly applicable to the study of tumorigenesis initiated by other cancer-predisposing mutations.

A key goal for the study of NF2-associated tumorigenesis will be the determination of what cell type gives rise to the schwannoma. It has been suggested that schwannomas express key markers of immature SCs (Hung et al. 2002). However, some studies have indicated a surprising capacity of differentiated (myelinating) SCs to dedifferentiate (Harrisingh et al. 2004). So, does loss of Merlin cause progressive dedifferentiation of a mature SC or proliferation of a SC progenitor? A detailed histological and ultrastructural analysis of the initiation and progression of schwannomas in Nf2-mutant mice and parallel comparison to human NF2-mutant schwannomas should help to answer this question. Similarly, comparative analyses of the development of meningiomas in NF2-mutant mice and humans together with the development and analysis of models of ependymoma will provide valuable insight into the pathogenesis of these tumors.

The identification of additional genetic mutations that supplant cooperate with $N f 2$ loss may provide important insight into the signaling pathways that are deregulated by $N f 2$ loss. For example, while the vast majority of sporadic schwannomas exhibit biallelic $N f 2$ inactivation, Nf2 mutations have been identified in only a subset of sporadic meningiomas (Ruttledge et al. 1994; Lomas et al. 2005). This suggests the existence of another locus, which, when mutated somatically, can cause meningioma development. Mathematical modeling of vestibular schwannoma development in NF2 patients suggests that in addition to loss of the wild-type Nf2 allele, one other mutational event may be necessary for the development of this tumor (Woods et al. 2003). In addition, the low incidence and late onset of schwannomas, in contrast to the high incidence of SC hyperplasia in $\mathrm{PO}$ $\mathrm{Cre} ; \mathrm{Nf} \mathrm{f}^{f l o \times 2 / f l o \times 2}$ mice strongly suggest that an additional mutation is required for the progression of SC hyperplasia to tumor formation (Giovannini et al. 1999, 2000; Stemmer-Rachamimov et al. 2004). Documentation of biallelic NF2 inactivation in preneoplastic lesions (hyperplastic SCs and tumorlets) of NF2 patients also supports this hypothesis (Stemmer-Rachamimov et al. 1998).

Many strategies will be exploited to continue the investigation of the molecular mechanism of Merlin function. It will be critical to precisely define the subcellular localization of Merlin in different cell types under different conditions and to functionally validate each candidate Merlin-interacting protein. The identification of 
higher order Merlin-containing complexes and examination of how such complexes respond to the loss of Merlin will provide important insight into how Merlin coordinates the physical and signaling properties of membrane complexes. In addition to further genetic analyses in Drosophila and investigation of $\mathrm{Nf}^{-{ }^{-}-}$cells from mutant mice, new studies of Merlin orthologs in other species that exploit the unique strengths of each model system will provide powerful, complementary strategies for mechanistic studies of Merlin function. Collectively, the study of NF2-associated tumorigenesis in mammals, together with basic cellular and molecular studies in other model systems and in cell culture will facilitate the identification of potential therapeutic targets and the development of therapeutic strategies for NF2. Further molecular investigation of this novel tumor suppressor will continue to provide new insight into how cells organize their interface with the extracellular environment to coordinate positional information and proliferation control and how disorganization of this interface contributes to tumorigenesis and metastasis.

\section{Acknowledgments}

It was very difficult to maintain the focus of this review given all of the interesting studies of NF2-we apologize to those whose work we have not cited or have only mentioned briefly due to space limitations. We are particularly grateful to Marcello Curto for much valuable input, and to Michel Kalamarides, Dominique Lallemand, and Angeliki Louvi for thoughtful discussions and valuable comments on the manuscript. M.G. is supported by the Department of Defense Neurofibromatosis Research Program, James S. McDonnell Foundation, Association Neurofibromatoses et Recklinghausen, Association pour la Recherche sur le Cancer (ARECA), Canceropôle Ile-de France, and Inserm. A.I.M. is supported by the Department of Defense Neurofibromatosis Research Program and National Institutes of Health.

\section{References}

Alfthan, K., Heiska, L., Gronholm, M., Renkema, G.H., and Carpen, O. 2004. Cyclic AMP-dependent protein kinase phosphorylates merlin at serine 518 independently of p21activated kinase and promotes merlin-ezrin heterodimerization. J. Biol. Chem. 279: 18559-18566.

Amsterdam, A., Sadler, K.C., Lai, K., Farrington, S., Bronson, R.T., Lees, J.A., and Hopkins, N. 2004. Many ribosomal protein genes are cancer genes in zebrafish. PLoS Biol. 2: E139.

Barret, C., Roy, C., Montcourrier, P., Mangeat, P., and Niggli, V. 2000. Mutagenesis of the phosphatidylinositol 4,5-bisphosphate (PIP(2)) binding site in the $\mathrm{NH}(2)$-terminal domain of ezrin correlates with its altered cellular distribution. J. Cell. Biol. 151: 1067-1080.

Berghmans, S., Murphey, R.D., Wienholds, E., Neuberg, D., Kutok, J.L., Fletcher, C.D., Morris, J.P., Liu, T.X., SchulteMerker, S., Kanki, J.P., et al. 2005. tp53 mutant zebrafish develop malignant peripheral nerve sheath tumors. Proc. Nat1. Acad. Sci. 102: 407-412.

Bershadsky, A. 2004. Magic touch: How does cell-cell adhesion trigger actin assembly? Trends Cell. Biol. 14: 589-593.

Bianchi, A.B., Mitsunaga, S.I., Cheng, J.Q., Klein, W.M., Jhan- war, S.C., Seizinger, B., Kley, N., Klein-Szanto, A.J., and Testa, J.R. 1995. High frequency of inactivating mutations in the neurofibromatosis type 2 gene (NF2) in primary malignant mesotheliomas. Proc. Natl. Acad. Sci. 92: 1085410858.

Brault, E., Gautreau, A., Lamarine, M., Callebaut, I., Thomas, G., and Goutebroze, L. 2001. Normal membrane localization and actin association of the NF2 tumor suppressor protein are dependent on folding of its $\mathrm{N}$-terminal domain. J. Cell. Sci. 114: 1901-1912.

Bretscher, A., Edwards, K., and Fehon, R.G. 2002. ERM proteins and merlin: Integrators at the cell cortex. Nat. Rev. Mol. Cell. Biol. 3: 586-599.

Cao, X., Ding, X., Guo, Z., Zhou, R., Wang, F., Long, F., Wu, F., Bi, F., Wang, Q., Fan, D., et al. 2005. PALS1 specifies the localization of ezrin to the apical membrane of gastric parietal cells. J. Biol. Chem. 280: 13584-13592.

Cavallaro, U. and Christofori, G. 2004. Multitasking in tumor progression: Signaling functions of cell adhesion molecules. Ann. N.Y. Acad. Sci. 1014: 58-66.

Chen, Y., Gutmann, D.H., Haipek, C.A., Martinsen, B.J., Bronner-Fraser, M., and Krull, C.E. 2004a. Characterization of chicken Nf2/merlin indicates regulatory roles in cell proliferation and migration. Dev. Dyn. 229: 541-554.

Chen, Y.X., Krull, C.E., and Reneker, L.W. 2004b. Targeted gene expression in the chicken eye by in ovo electroporation. Mol. Vis. 10: 874-883.

Del Bigio, M.R. 1995. The ependyma: A protective barrier between brain and cerebrospinal fluid. Glia 14: 1-13.

den Bakker, M.A., Tascilar, M., Riegman, P.H., Hekman, A.C., Boersma, W., Janssen, P.J., de Jong, T.A., Hendriks, W., van der Kwast, T.H., and Zwarthoff, E.C. 1995. Neurofibromatosis type 2 protein co-localizes with elements of the cytoskeleton. Am. J. Pathol. 147: 1339-1349.

Denisenko-Nehrbass, N., Faivre-Sarrailh, C., Goutebroze, L., and Girault, J.A. 2002. A molecular view on paranodal junctions of myelinated fibers. J. Physiol. Paris 96: 99-103.

Ebert, C., von Haken, M., Meyer-Puttlitz, B., Wiestler, O.D., Reifenberger, G., Pietsch, T., and von Deimling, A. 1999. Molecular genetic analysis of ependymal tumors. NF2 mutations and chromosome 22q loss occur preferentially in intramedullary spinal ependymomas. Am. J. Pathol. 155: 627632.

Erlandson, R.A. and Woodruff, J.M. 1982. Peripheral nerve sheath tumors: An electron microscopic study of 43 cases. Cancer 49: 273-287.

Evans, D.G., Huson, S.M., Donnai, D., Neary, W., Blair, V., Newton, V., and Harris, R. 1992. A clinical study of type 2 neurofibromatosis. Q. J. Med. 84: 603-618.

Evans, D.G., Moran, A., King, A., Saeed, S., Gurusinghe, N., and Ramsden, R. 2005. Incidence of vestibular schwannoma and neurofibromatosis 2 in the North West of England over a 10-year period: Higher incidence than previously thought. Otol. Neurotol. 26: 93-97.

Fehon, R.G., Oren, T., LaJeunesse, D.R., Melby, T.E., and McCartney, B.M. 1997. Isolation of mutations in the Drosophila homologues of the human Neurofibromatosis 2 and yeast CDC42 genes using a simple and efficient reverse-genetic method. Genetics 146: 245-252.

Fernandez-Valle, C., Tang, Y., Ricard, J., Rodenas-Ruano, A., Taylor, A., Hackler, E., Biggerstaff, J., and Iacovelli, J. 2002. Paxillin binds schwannomin and regulates its density-dependent localization and effect on cell morphology. Nat. Genet. 31: 354-362.

Fleury-Feith, J., Lecomte, C., Renier, A., Matrat, M., Kheuang, L., Abramowski, V., Levy, F., Janin, A., Giovannini, M., and 
Jaurand, M.C. 2003. Hemizygosity of Nf2 is associated with increased susceptibility to asbestos-induced peritoneal tumours. Oncogene 22: 3799-3805.

Garratt, A.N., Britsch, S., and Birchmeier, C. 2000. Neuregulin, a factor with many functions in the life of a schwann cell. Bioessays 22: 987-996.

Gautreau, A., Manent, J., Fievet, B., Louvard, D., Giovannini, M., and Arpin, M. 2002. Mutant products of the NF2 tumor suppressor gene are degraded by the ubiquitin-proteasome pathway. J. Biol. Chem. 277: 31279-31282.

Giovannini, M., Robanus-Maandag, E., Niwa-Kawakita, M., van der Valk, M., Woodruff, J.M., Goutebroze, L., Merel, P., Berns, A., and Thomas, G. 1999. Schwann cell hyperplasia and tumors in transgenic mice expressing a naturally occurring mutant NF2 protein. Genes \& Dev. 13: 978-986.

Giovannini, M., Robanus-Maandag, E., van der Valk, M., NiwaKawakita, M., Abramowski, V., Goutebroze, L., Woodruff, J.M., Berns, A., and Thomas, G. 2000. Conditional biallelic $\mathrm{Nf} 2$ mutation in the mouse promotes manifestations of human neurofibromatosis type 2. Genes \& Dev. 14: 1617-1630.

Gobel, V., Barrett, P.L., Hall, D.H., and Fleming, J.T. 2004. Lumen morphogenesis in $C$. elegans requires the membranecytoskeleton linker erm-1. Dev. Cell 6: 865-873.

Gonzalez-Agosti, C., Xu, L., Pinney, D., Beauchamp, R., Hobbs, W., Gusella, J., and Ramesh, V. 1996. The merlin tumor suppressor localizes preferentially in membrane ruffles. Oncogene 13: 1239-1247.

Gotow, T. and Hashimoto, P.H. 1982. Intercellular junctions between specialized ependymal cells in the subcommissural organ of the rat. J. Neurocytol. 11: 363-379.

Gronholm, M., Sainio, M., Zhao, F., Heiska, L., Vaheri, A., and Carpen, O. 1999. Homotypic and heterotypic interaction of the neurofibromatosis 2 tumor suppressor protein merlin and the ERM protein ezrin. J. Cell. Sci. 112: 895-904.

Gronholm, M., Teesalu, T., Tyynela, J., Piltti, K., Bohling, T., Wartiovaara, K., Vaheri, A., and Carpen, O. 2005. Characterization of the NF2 protein merlin and the ERM protein ezrin in human, rat, and mouse central nervous system. Mol. Cell. Neurosci. 28: 683-693.

Harrisingh, M.C., Perez-Nadales, E., Parkinson, D.B., Malcolm, D.S., Mudge, A.W., and Lloyd, A.C. 2004. The Ras/Raf/ERK signalling pathway drives Schwann cell dedifferentiation. EMBO J. 23: 3061-3071.

Heinrich, B., Hartmann, C., Stemmer-Rachamimov, A.O., Louis, D.N., and MacCollin, M. 2003. Multiple meningiomas: Investigating the molecular basis of sporadic and familial forms. Int. J. Cancer 103: 483-488.

Hipfner, D.R., Keller, N., and Cohen, S.M. 2004. Slik Sterile-20 kinase regulates Moesin activity to promote epithelial integrity during tissue growth. Genes \& Dev. 18: 2243-2248.

Hung, G., Colton, J., Fisher, L., Oppenheimer, M., Faudoa, R., Slattery, W., and Linthicum, F. 2002. Immunohistochemistry study of human vestibular nerve schwannoma differentiation. Glia 38: 363-370.

James, M.F., Manchanda, N., Gonzalez-Agosti, C., Hartwig, J.H., and Ramesh, V. 2001. The neurofibromatosis 2 protein product merlin selectively binds F-actin but not G-actin, and stabilizes the filaments through a lateral association. Biochem. J. 356: 377-386.

Johnson, K.C., Kissil, J.L., Fry, J.L., and Jacks, T. 2002. Cellular transformation by a FERM domain mutant of the Nf2 tumor suppressor gene. Oncogene 21: 5990-5997.

Johnstone, R.W., Ruefli, A.A., and Lowe, S.W. 2002. Apoptosis: A link between cancer genetics and chemotherapy. Cell 108: $153-164$.

Kalamarides, M., Niwa-Kawakita, M., Leblois, H., Abramowski,
V., Perricaudet, M., Janin, A., Thomas, G., Gutmann, D.H., and Giovannini, M. 2002. Nf2 gene inactivation in arachnoidal cells is rate-limiting for meningioma development in the mouse. Genes \& Dev. 16: 1060-1065.

Kissil, J.L., Johnson, K.C., Eckman, M.S., and Jacks, T. 2002. Merlin phosphorylation by 21 -activated kinase 2 and effects of phosphorylation on merlin localization. J. Biol. Chem. 277: 10394-10399.

Kissil, J.L., Wilker, E.W., Johnson, K.C., Eckman, M.S., Yaffe, M.B., and Jacks, T. 2003. Merlin, the product of the Nf2 tumor suppressor gene, is an inhibitor of the p21-activated kinase, Pak1. Mol. Cell 12: 841-849.

Kolch, W. 2003. Erbin: Sorting out ErbB2 receptors or giving Ras a break? Sci. STKE 2003: pe37.

Kressel, M. and Schmucker, B. 2002. Nucleocytoplasmic transfer of the NF2 tumor suppressor protein merlin is regulated by exon 2 and a CRM1-dependent nuclear export signal in exon 15. Hum. Mol. Genet. 11: 2269-2278.

Lagunowich, L.A., Schneider, J.C., Chasen, S., and Grunwald, G.B. 1992. Immunohistochemical and biochemical analysis of N-cadherin expression during CNS development. J. Neurosci. Res. 32: 202-208.

LaJeunesse, D.R., McCartney, B.M., and Fehon, R.G. 1998. Structural analysis of Drosophila merlin reveals functional domains important for growth control and subcellular localization. J. Cell. Biol. 141: 1589-1599.

LaJeunesse, D.R., McCartney, B.M., and Fehon, R.G. 2001. A systematic screen for dominant second-site modifiers of Merlin/NF2 phenotypes reveals an interaction with blistered/DSRF and scribbler. Genetics 158: 667-679.

Lallemand, D., Curto, M., Saotome, I., Giovannini, M., and McClatchey, A.I. 2003. NF2 deficiency promotes tumorigenesis and metastasis by destabilizing adherens junctions. Genes \& Dev. 17: 1090-1100.

Lampugnani, M.G., Zanetti, A., Corada, M., Takahashi, T., Balconi, G., Breviario, F., Orsenigo, F., Cattelino, A., Kemler, R., Daniel, T.O., et al. 2003. Contact inhibition of VEGF-induced proliferation requires vascular endothelial cadherin, $\beta$-catenin, and the phosphatase DEP-1/CD148. J. Cell Biol. 161: 793-804.

Lasota, J., Fetsch, J.F., Wozniak, A., Wasag, B., Sciot, R., and Miettinen, M. 2001. The neurofibromatosis type 2 gene is mutated in perineurial cell tumors: A molecular genetic study of eight cases. Am. J. Pathol. 158: 1223-1229.

Lazar, C.S., Cresson, C.M., Lauffenburger, D.A., and Gill, G.N. 2004. The $\mathrm{Na}+\mathrm{H}+$ exchanger regulatory factor stabilizes epidermal growth factor receptors at the cell surface. Mol. Biol. Cell 15: 5470-5480.

Lippoldt, A., Jansson, A., Kniesel, U., Andbjer, B., Andersson, A., Wolburg, H., Fuxe, K., and Haller, H. 2000. Phorbol ester induced changes in tight and adherens junctions in the choroid plexus epithelium and in the ependyma. Brain Res. 854: 197-206.

Lomas, J., Bello, M.J., Arjona, D., Alonso, M.E., Martinez-Glez, V., Lopez-Marin, I., Aminoso, C., de Campos, J.M., Isla, A., Vaquero, J., et al. 2005. Genetic and epigenetic alteration of the NF2 gene in sporadic meningiomas. Genes Chrom. Cancer 42: 314-319.

Louis, D.N., Scheithauer, B.W., Budka, H., von Deimling, A., and Kepes, J.J. 2000. Meningiomas. IARC Press, Lyon, France.

Lutchman, M. and Rouleau, G.A. 1995. The neurofibromatosis type 2 gene product, schwannomin, suppresses growth of NIH 3T3 cells. Cancer Res. 55: 2270-2274.

MacDougall, N., Lad, L., Wilkie, G.S., Francis-Lang, H., Sullivan, W., and Davis, I. 2001. Merlin, the Drosophila homologue of neurofibromatosis-2, is specifically required in pos- 
terior follicle cells for axis formation in the oocyte. Development 128: 665-673.

Maeda, M., Matsui, T., Imamura, M., Tsukita, S., and Tsukita, S. 1999. Expression level, subcellular distribution and rhoGDI binding affinity of merlin in comparison with Ezrin/ Radixin/Moesin proteins. Oncogene 18: 4788-4797.

Manchanda, N., Lyubimova, A., Ho, H.Y., James, M.F., Gusella, J.F., Ramesh, N., Snapper, S.B., and Ramesh, V. 2005. The NF2 tumor suppressor Merlin and the ERM proteins interact with N-WASP and regulate its actin polymerization function. J. Biol. Chem. 280: 12517-12522.

Matsui, T., Maeda, M., Doi, Y., Yonemura, S., Amano, M., Kaibuchi, K., Tsukita, S., and Tsukita, S. 1998. Rho-kinase phosphorylates $\mathrm{COOH}$-terminal threonines of ezrin/radixin/ moesin (ERM) proteins and regulates their head-to-tail association. J. Cell. Biol. 140: 647-657.

Matsui, T., Yonemura, S., Tsukita, S., and Tsukita, S. 1999. Activation of ERM proteins in vivo by Rho involves phosphatidyl-inositol 4-phosphate 5-kinase and not ROCK kinases. Curr. Biol. 9: 1259-1262.

McCartney, B.M. and Fehon, R.G. 1996. Distinct cellular and subcellular patterns of expression imply distinct functions for the Drosophila homologues of moesin and the neurofibromatosis 2 tumor suppressor, merlin. J. Cell. Biol. 133: 843-852.

McClatchey, A.I. 2003. Merlin and ERM proteins: Unappreciated roles in cancer development? Nat. Rev. Cancer 3: 877883.

McClatchey, A.I., Saotome, I., Ramesh, V., Gusella, J.F., and Jacks, T. 1997. The Nf2 tumor suppressor gene product is essential for extraembryonic development immediately prior to gastrulation. Genes \& Dev. 11: 1253-1265.

McClatchey, A.I., Saotome, I., Mercer, K., Crowley, D., Gusella, J.F., Bronson, R.T., and Jacks, T. 1998. Mice heterozygous for a mutation at the Nf2 tumor suppressor locus develop a range of highly metastatic tumors. Genes \& Dev. 12: 11211133.

McMenamin, M.E. and Fletcher, C.D. 2001. Expanding the spectrum of malignant change in schwannomas: Epithelioid malignant change, epithelioid malignant peripheral nerve sheath tumor, and epithelioid angiosarcoma: A study of 17 cases. Am. J. Surg. Pathol. 25: 13-25.

Meng, J.J., Lowrie, D.J., Sun, H., Dorsey, E., Pelton, P.D., Bashour, A.M., Groden, J., Ratner, N., and Ip, W. 2000. Interaction between two isoforms of the NF2 tumor suppressor protein, merlin, and between merlin and ezrin, suggests modulation of ERM proteins by merlin. J. Neurosci. Res. 62: 491-502.

Michailov, G.V., Sereda, M.W., Brinkmann, B.G., Fischer, T.M., Haug, B., Birchmeier, C., Role, L., Lai, C., Schwab, M.H., and Nave, K.A. 2004. Axonal neuregulin-1 regulates myelin sheath thickness. Science 304: 700-703.

Morrison, H., Sherman, L.S., Legg, J., Banine, F., Isacke, C., Haipek, C.A., Gutmann, D.H., Ponta, H., and Herrlich, P. 2001. The NF2 tumor suppressor gene product, merlin, mediates contact inhibition of growth through interactions with CD44. Genes \& Dev. 15: 968-980.

Muranen, T., Gronholm, M., Renkema, G.H., and Carpen, O. 2005. Cell cycle-dependent nucleocytoplasmic shuttling of the neurofibromatosis 2 tumour suppressor merlin. Oncogene 24: 1150-1158.

Murthy, A., Gonzalez-Agosti, C., Cordero, E., Pinney, D., Candia, C., Solomon, F., Gusella, J., and Ramesh, V. 1998. NHE$\mathrm{RF}$, a regulatory cofactor for $\mathrm{Na}(+)-\mathrm{H}+$ exchange, is a common interactor for merlin and ERM (MERM) proteins. J. Biol. Chem. 273: 1273-1276.

Nag, S. 1997. Ependyma. In Textbook of neuropathology (eds.
R.L. Davis and D.M. Robertson), pp 111-136. Williams \& Wilkins, Baltimore, MD.

Nguyen, R., Reczek, D., and Bretscher, A. 2001. Hierarchy of merlin and ezrin $\mathrm{N}$ - and $\mathrm{C}$-terminal domain interactions in homo- and heterotypic associations and their relationship to binding of scaffolding proteins EBP50 and E3KARP. J. Biol. Chem. 276: 7621-7629.

Pearson, M.A., Reczek, D., Bretscher, A., and Karplus, P.A. 2000. Structure of the ERM protein moesin reveals the FERM domain fold masked by an extended actin binding tail domain. Cell 101: 259-270.

Peles, E. and Salzer, J.L. 2000. Molecular domains of myelinated axons. Curr. Opin. Neurobiol. 10: 558-565.

Pelton, P.D., Sherman, L.S., Rizvi, T.A., Marchionni, M.A., Wood, P., Friedman, R.A., and Ratner, N. 1998. Ruffling membrane, stress fiber, cell spreading and proliferation abnormalities in human Schwannoma cells. Oncogene 17: 2195-2209.

Peters, A., Palay, S.L., and Webster, H.D. 1991. The fine structure of the nervous system. Neurons and their supporting cells. Oxford University Press, New York.

Pietromonaco, S.F., Simons, P.C., Altman, A., and Elias, L. 1998. Protein kinase C- $\theta$ phosphorylation of moesin in the actin-binding sequence. J. Biol. Chem. 273: 7594-7603.

Pineau, P., Marchio, A., Nagamori, S., Seki, S., Tiollais, P., and Dejean, A. 2003. Homozygous deletion scanning in hepatobiliary tumor cell lines reveals alternative pathways for liver carcinogenesis. Hepatology 37: 852-861.

Qian, X., Karpova, T., Sheppard, A.M., McNally, J., and Lowy, D.R. 2004. E-cadherin-mediated adhesion inhibits ligand-dependent activation of diverse receptor tyrosine kinases. EMBO J. 23: 1739-1784.

Rangwala, R., Banine, F., Borg, J.P., and Sherman, L.S. 2005. Erbin regulates mitogen-activated protein (MAP) kinase activation and MAP kinase-dependent interactions between Merlin and adherens junction protein complexes in Schwann cells. J. Biol. Chem. 280: 11790-11797.

Redzic, Z.B. and Segal, M.B. 2004. The structure of the choroid plexus and the physiology of the choroid plexus epithelium. Adv. Drug Deliv. Rev. 56: 1695-1716.

Robanus-Maandag, E., Giovannini, M., van der Valk, M., NiwaKawakita, M., Abramowski, V., Antonescu, C., Thomas, G., and Berns, A. 2004. Synergy of Nf2 and p53 mutations in development of malignant tumours of neural crest origin. Oncogene 23: 6541-6547.

Rong, R., Surace, E.I., Haipek, C.A., Gutmann, D.H., and Ye, K. 2004. Serine 518 phosphorylation modulates merlin intramolecular association and binding to critical effectors important for NF2 growth suppression. Oncogene 23: 84478454.

Rouleau, G.A., Merel, P., Lutchman, M., Sanson, M., Zucman, J., Marineau, C., Hoang-Xuan, K., Demczuk, S., Desmaze, C., Plougastel, B., et al. 1993. Alteration in a new gene encoding a putative membrane-organizing protein causes neuro-fibromatosis type 2. Nature 363: 515-521.

Ruttledge, M.H., Sarrazin, J., Rangaratnam, S., Phelan, C.M., Twist, E., Merel, P., Delattre, O., Thomas, G., Nordenskjold, M., Collins, V.P., et al. 1994. Evidence for the complete inactivation of the NF2 gene in the majority of sporadic meningiomas. Nat. Genet. 6: 180-184.

Sainio, M., Zhao, F., Heiska, L., Turunen, O., den Bakker, M., Zwarthoff, E., Lutchman, M., Rouleau, G.A., Jaaskelainen, J., Vaheri, A., et al. 1997. Neurofibromatosis 2 tumor suppressor protein colocalizes with ezrin and CD44 and associates with actin-containing cytoskeleton. I. Cell. Sci. 110: 2249-2260. 
Salzer, J.L. 2003. Polarized domains of myelinated axons. Neuron 40: 297-318.

Salzer, J.L., Bunge, R.P., and Glaser, L. 1980a. Studies of Schwann cell proliferation. III. Evidence for the surface localization of the neurite mitogen. J. Cell. Biol. 84: 767-778.

Salzer, J.L., Williams, A.K., Glaser, L., and Bunge, R.P. 1980b. Studies of Schwann cell proliferation. II. Characterization of the stimulation and specificity of the response to a neurite membrane fraction. J. Cell. Biol. 84: 753-766.

Scherer, S.S. and Gutmann, D.H. 1996. Expression of the neurofibromatosis 2 tumor suppressor gene product, merlin, in Schwann cells. J. Neurosci. Res. 46: 595-605.

Scoles, D.R., Huynh, D.P., Morcos, P.A., Coulsell, E.R., Robinson, N.G., Tamanoi, F., and Pulst, S.M. 1998. Neurofibromatosis 2 tumour suppressor schwannomin interacts with BII-spectrin. Nat. Genet. 18: 354-359.

Scoles, D.R., Huynh, D.P., Chen, M.S., Burke, S.P., Gutmann, D.H., and Pulst, S.M. 2000. The neurofibromatosis 2 tumor suppressor protein interacts with hepatocyte growth factorregulated tyrosine kinase substrate. Hum. Mol. Genet. 9: $1567-1574$.

Sekido, Y., Pass, H.I., Bader, S., Mew, D.J., Christman, M.F., Gazdar, A.F., and Minna, J.D. 1995. Neurofibromatosis type 2 (NF2) gene is somatically mutated in mesothelioma but not in lung cancer. Cancer Res. 55: 1227-1231.

Shaw, R.J., McClatchey, A.I., and Jacks, T. 1998. Regulation of the neurofibromatosis type 2 tumor suppressor protein, merlin, by adhesion and growth arrest stimuli. J. Biol. Chem. 273: 7757-7764.

Shaw, R.J., Paez, J.G., Curto, M., Yaktine, A., Pruitt, W.M., Saotome, I., O'Bryan, J.P., Gupta, V., Ratner, N., Der, C.J., et al. 2001. The Nf2 tumor suppressor, merlin, functions in Racdependent signaling. Dev. Cell 1: 63-72.

Sheikh, H.A., Tometsko, M., Niehouse, L., Aldeeb, D., Swalsky, P., Finkelstein, S., Barnes, E.L., and Hunt, J.L. 2004. Molecular genotyping of medullary thyroid carcinoma can predict tumor recurrence. Am. J. Surg. Pathol. 28: 101-106.

Shelly, M., Mosesson, Y., Citri, A., Lavi, S., Zwang, Y., Melamed-Book, N., Aroeti, B., and Yarden, Y. 2003. Polar expression of ErbB-2/HER2 in epithelia. Bimodal regulation by Lin7. Dev. Cell 5: 475-486.

Sherman, L., Xu, H.M., Geist, R.T., Saporito-Irwin, S., Howells, N., Ponta, H., Herrlich, P., and Gutmann, D.H. 1997. Interdomain binding mediates tumor growth suppression by the NF2 gene product. Oncogene 15: 2505-2509.

Sherr, C.J. 2004. Principles of tumor suppression. Cell 116: 235 246.

Shimizu, T., Seto, A., Maita, N., Hamada, K., Tsukita, S., Tsukita, S., and Hakoshima, T. 2002. Structural basis for neurofibromatosis type 2. Crystal structure of the merlin FERM domain. J. Biol. Chem. 277: 10332-10336.

Speck, O., Hughes, S.C., Noren, N.K., Kulikauskas, R.M., and Fehon, R.G. 2003. Moesin functions antagonistically to the Rho pathway to maintain epithelial integrity. Nature 421: 83-87.

Stemmer-Rachamimov, A.O., Xu, L., Gonzalez-Agosti, C., Burwick, J.A., Pinney, D., Beauchamp, R., Jacoby, L.B., Gusella, J.F., Ramesh, V., and Louis, D.N. 1997. Universal absence of merlin, but not other ERM family members, in schwannomas. Am. J. Pathol. 151: 1649-1654.

Stemmer-Rachamimov, A.O., Nielsen, G.P., Rosenberg, A.E., Louis, D.N., Jones, D., Ramesh, V., Gusella, J.F., and Jacoby, L.B. 1998. The NF2 gene and merlin protein in human osteosarcomas. Neurogenetics 2: 73-74.

Stemmer-Rachamimov, A.O., Louis, D.N., Nielsen, G.P., Anto- nescu, C.R., Borowsky, A.D., Bronson, R.T., Burns, D.K., Cervera, P., McLaughlin, M.E., Reifenberger, G., et al. 2004. Comparative pathology of nerve sheath tumors in mouse models and humans. Cancer Res. 64: 3718-3724.

Stickney, J.T., Bacon, W.C., Rojas, M., Ratner, N., and Ip, W. 2004. Activation of the tumor suppressor merlin modulates its interaction with lipid rafts. Cancer Res. 64: 2717-2724.

Takahashi, K. and Suzuki, K. 1996. Density-dependent inhibition of growth involves prevention of EGF receptor activation by E-cadherin-mediated cell-cell adhesion. Exp. Cell Res. 226: 214-222.

Takahashi, K., Sasaki, T., Mammoto, A., Takaishi, K., Kameyama, T., Tsukita, S., and Takai, Y. 1997. Direct interaction of the Rho GDP dissociation inhibitor with ezrin/radixin/ moesin initiates the activation of the Rho small G protein. J. Biol. Chem. 272: 23371-23375.

Tikoo, A., Varga, M., Ramesh, V., Gusella, J., and Maruta, H. 1994. An anti-Ras function of neurofibromatosis type 2 gene product (NF2/Merlin). J. Biol. Chem. 269: 23387-23390.

Tohma, Y., Yamashima, T., and Yamashita, J. 1992. Immunohistochemical localization of cell adhesion molecule epithelial cadherin in human arachnoid villi and meningiomas. Cancer Res. 52: 1981-1987.

Trofatter, J.A., MacCollin, M.M., Rutter, J.L., Murrell, J.R., Duyao, M.P., Parry, D.M., Eldridge, R., Kley, N., Menon, A.G., Pulaski, K., et al. 1993. A novel moesin-, ezrin-, radixin-like gene is a candidate for the neurofibromatosis 2 tumor suppressor. Cell 72: 791-800.

Wiederhold, T., Lee, M.F., James, M., Neujahr, R., Smith, N., Murthy, A., Hartwig, J., Gusella, J.F., and Ramesh, V. 2004. Magicin, a novel cytoskeletal protein associates with the NF2 tumor suppressor merlin and Grb2. Oncogene 23: $8815-8825$.

Woodruff, J.M., Selig, A.M., Crowley, K., and Allen, P.W. 1994. Schwannoma (neurilemoma) with malignant transformation. A rare, distinctive peripheral nerve tumor. Am. J. Surg. Pathol. 18: 882-895.

Woods, R., Friedman, J.M., Evans, D.G., Baser, M.E., and Joe, H. 2003. Exploring the 'two-hit hypothesis' in NF2: Tests of two-hit and three-hit models of vestibular schwannoma development. Genet. Epidemiol. 24: 265-272.

Xiao, G.H., Beeser, A., Chernoff, J., and Testa, J.R. 2002. p21activated kinase links Rac/Cdc42 signaling to merlin. J. Biol. Chem. 277: 883-886.

Yamashima, T. 1996. On arachnoid villi and meningiomas: Functional implication of ultrastructure, cell adhesion mechanisms, and extracellular matrix composition. Pathol. Oncol. Res. 2: 144-149.

Yamashima, T., Tohma, Y., and Yamashita, J. 1992. Expression of cell adhesion molecule E-cadherin in human arachnoid villi. J. Neurosurg. 77: 749-756.

Zhu, Y., Ghosh, P., Charnay, P., Burns, D.K., and Parada, L.F. 2002. Neurofibromas in NF1: Schwann cell origin and role of tumor environment. Science 296: 920-922. 


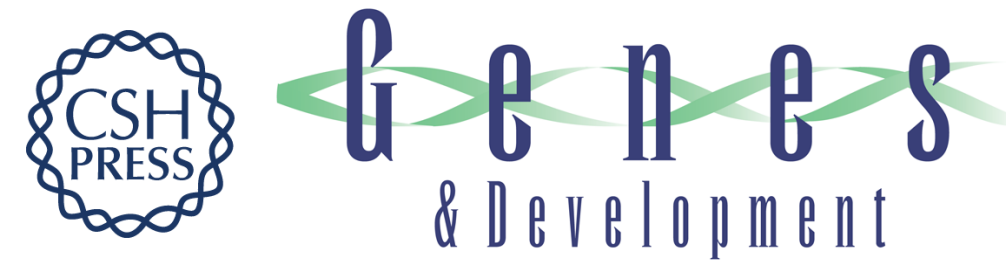

\section{Membrane organization and tumorigenesis--the NF2 tumor suppressor, Merlin}

Andrea I. McClatchey and Marco Giovannini

Genes Dev. 2005, 19:

Access the most recent version at doi:10.1101/gad.1335605

References This article cites 112 articles, 48 of which can be accessed free at: http://genesdev.cshlp.org/content/19/19/2265.full.html\#ref-list-1

License

Email Alerting Receive free email alerts when new articles cite this article - sign up in the box at the top Service right corner of the article or click here.

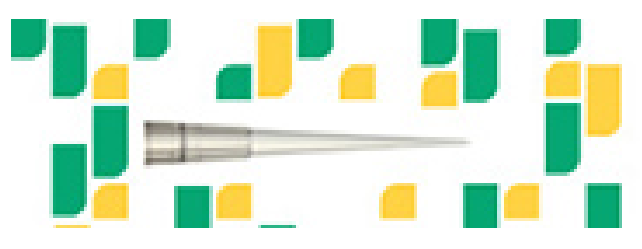

Focused on your science. 